\title{
Oral mosapride can provide additional anti- emetic efficacy following total joint arthroplasty under general anesthesia: a randomized, double-blinded clinical trial
}

\author{
Jinwei Xie ${ }^{1}$, Yingchun $\mathrm{Cai}^{1,2}$, Jun Ma ${ }^{1}$, Qiang Huang ${ }^{1}$ and Fuxing Pei ${ }^{1 *}$ (D)
}

\begin{abstract}
Background: We sought to determine (1) whether the addition of prophylactic oral mosapride to a protocol including dexamethasone and ondansetron further reduces postoperative nausea and vomiting (PONV) compared with ondansetron alone or the combination of both; (2) whether preemptive application of oral mosapride provides additional clinical benefits for bowel function and appetite, thus improving functional recovery.

Methods: We randomized 240 patients undergoing total hip and knee arthroplasty to receive placebo (Control, $n=80$ ), dexamethasone $(10 \mathrm{mg}$ ) before anesthesia induction (Dexa, $n=82)$, or dexamethasone $(10 \mathrm{mg})$ before anesthesia induction as well as oral mosapride $(5 \mathrm{mg})$ before and after surgery (Mosa+Dexa, $n=78$ ). Patients were assessed at 0-6, 6-12, 12-24, and 24-48 h postoperatively. Primary outcomes were incidence and severity of PONV as well as complete response. Secondary outcomes were appetite, time until first defecation and ambulation, patient satisfaction score, and length of hospital stay.
\end{abstract}

Results: Mosa+Dexa patients showed significantly lower incidence of nausea at 6-12 h (3.8\%) and over the entire evaluation period (6.4\%), as well as a higher rate of complete response (89.7\%) than other patients. Mosa+Dexa patients required less time to achieve first defecation and ambulation, they were hospitalized for shorter time, and they were more satisfied with clinical care.

Conclusion: Addition of oral mosapride further reduced incidence of PONV, especially postoperative nausea, during 6-12 $\mathrm{h}$ postoperatively. Moreover, preemptive application of oral mosapride can further improve appetite, bowel function, ambulation and length of hospital stay.

Trial registration: The study protocol was registered at the Chinese Clinical Trial Registry (ChiCTR1800015896), prospectively registered on 27/04/2018.

Keywords: PONV, Total joint arthroplasty, General anesthesia, Bowel function

\footnotetext{
*Correspondence: peifuxinghuaxi@126.com

'Department of Orthopaedic Surgery, National Clinical Research Center for

Geriatrics, West China Hospital, Sichuan University, No. 37 Guoxue Road,

Chengdu, Sichuan Province 610041, People's Republic of China

Full list of author information is available at the end of the article
}

(c) The Author(s). 2020 Open Access This article is licensed under a Creative Commons Attribution 4.0 International License, which permits use, sharing, adaptation, distribution and reproduction in any medium or format, as long as you give appropriate credit to the original author(s) and the source, provide a link to the Creative Commons licence, and indicate if changes were made. The images or other third party material in this article are included in the article's Creative Commons licence, unless indicated otherwise in a credit line to the material. If material is not included in the article's Creative Commons licence and your intended use is not permitted by statutory regulation or exceeds the permitted use, you will need to obtain permission directly from the copyright holder. To view a copy of this licence, visit http://creativecommons.org/licenses/by/4.0/. The Creative Commons Public Domain Dedication waiver (http://creativecommons.org/publicdomain/zero/1.0/) applies to the data made available in this article, unless otherwise stated in a credit line to the data. 


\section{Background}

Total hip and knee arthroplasty remain one of the most commonly performed major orthopedic procedures; the number of procedures in most countries has increased rapidly over the past decades [1, 2]. Postoperative nausea and vomiting (PONV) are one of the most common and distressing complications after surgery, especially when the surgery is performed under general anesthesia: PONV occurs in $25-30 \%$ of all patients, and the rate can reach $80 \%$ among at-risk patients without prophylactic intervention $[3,4]$. PONV can lead to dehydration, hypertension and other postoperative morbidities, which may prolong hospital stay and increase risk of readmission, raising healthcare costs [5]. This was a paradox in the circumstance that surgeons and healthcare providers have been shifting their focus from the surgical technique to perioperative management in order to improve patients' psychological and functional recovery [6].

Several prophylactic interventions have been reported to prevent and treat PONV, e.g. 5- $\mathrm{HT}_{3}$ receptor antagonists, NK-1 receptor antagonists, corticosteroids, butyrophenone and antihistamines [7]. While these measures can be effective, PONV remains a persistent problem [8, 9]. One reason for this persistence is the gap between implementation and our goal of a "PONV-free hospital". We previously found that PONV occurred in up to $48.8 \%$ of patients undergoing total joint arthroplasty under general anesthesia at our medical center (unpublished data). Another reason for this persistence is that anti-PONV measures can be associated with adverse effects. For example, use of the $5-\mathrm{HT}_{3}$ receptor antagonist ondansetron can aggravate the postoperative constipation that occurs in up to $65 \%$ of total joint arthroplasty patients [10]. We have shown that low-dose dexamethasone can reduce the incidence of PONV following total hip and knee arthroplasty $[11,12]$, but it can be contraindicated in the presence of diabetes or gastrointestinal ulcers. Therefore, it's necessary and practical to search for other antiemetic protocol.

The major risk factor of PONV is use of opioids, which can stimulate the release of 5 - HT and inhibit gastrointestinal peristalsis [13]]. Indeed, selective $5-\mathrm{HT}_{4}$ agonists can stimulate the gastrointestinal tract and promote motility [14]. The selective $5-\mathrm{HT}_{4}$ agonist mosapride can reduce vomiting caused by chemotherapy [15]. This inspired us to examine whether the anti-emetic effects of oral mosapride might offer clinical benefits for total joint arthroplasty patients.

Thus, we sought to determine in the present study (1) whether the addition of prophylactic oral mosapride to a protocol including dexamethasone and ondansetron can further reduce PONV compared with ondansetron alone or the combination of both; and (2) whether preemptive application of oral mosapride can provide additional clinical benefits for recovery of bowel function and appetite.

\section{Methods}

Study design

This prospective, randomized, clinical trial was performed on patients undergoing primary total hip or knee arthroplasty between November 2017 and December 2018. Institutional review board approval (2012-268) was obtained before the enrollment of patients. All patients provided written informed consent and research authorization before surgery. The study was conducted in compliance with the recommendations of the CONSORT Statement and the Declaration of Helsinki. The study protocol was registered at the Chinese Clinical Trial Registry (ChiCTR1800015896).

\section{Participants}

Eligible patients included those at least 18 years old who were at risk of PONV (at least 1 score of Apfel), and scheduled for primary total hip or knee arthroplasty for endstage joint diseases such as osteoarthritis, development dysplasia of hip, and osteonecrosis of the femoral head. Exclusion criteria included a history of intolerance of any drugs used in the current study, administration of another antiemetic drug or systemic steroid within $24 \mathrm{~h}$ before surgery, allergy to experimental drugs or history of adverse reactions, diabetes with poor blood glucose control, history of steroid or immunosuppressive drug use within the previous 6 months, history of cardiac disease such as heart failure, heart block, ventricular arrhythmia or severe impairment of bowel motility, renal function or hepatic function.

\section{Randomization and treatment}

Patients in this double-blind study were randomly allocated into three groups using a computer-generated randomization list in a 1: 1: 1 ratio. A random allocation sequence concealed in opaque sealed envelopes only opened before surgery. The control group received $2 \mathrm{ml}$ of normal saline during anesthesia induction, followed by oral placebo at $3 \mathrm{~h}$ before surgery and three times per day after surgery. The Dexa group received $10 \mathrm{mg}$ of dexamethasone (in $2 \mathrm{ml}$ ) during anesthesia induction, as well as oral placebo at $3 \mathrm{~h}$ before surgery and three times per day after surgery. The Mosa+Dexa group received $10 \mathrm{mg}$ of dexamethasone (in $2 \mathrm{ml}$ ) during anesthesia induction, as well as $5 \mathrm{mg}$ of oral Mosapride at $3 \mathrm{~h}$ before surgery and three times per day after surgery. Dexamethasone was administered intraoperatively by the anesthesiologist and oral drugs were given postoperatively by nurses who were not involved in the study. Patients, surgeons, data collectors and analysts were blinded to group allocation.

\section{Anesthesia and perioperative pain management}

All surgeries were performed under general anesthesia by the same surgeons; standard medial parapatellar arthrotomy was performed for total knee arthroplasty, 
and the posterolateral approach was used for total hip arthroplasty. A cemented posteriorly stabilized prosthesis was implanted in all total knee arthroplasty patients, and cementless acetabular and femoral components were implanted in total hip arthroplasty patients.

All patients received the same anesthetic regimen and multimodal pain management protocol. Cefuroxime (1.5 g) was given intravenously as prophylactic antibiotic prior to incision. Sufentanil $(0.2 \mu \mathrm{g} / \mathrm{kg})$ propofol $(2 \mathrm{mg} /$ $\mathrm{kg})$, atracurium $(1 \mathrm{mg} / \mathrm{kg})$ and midazolam $(2 \mathrm{mg})$ were used for anesthesia induction. Then sufentanil $(0.1 \mu \mathrm{g} /$ $\mathrm{kg})$, atracurium $(0.5 \mathrm{mg} / \mathrm{kg})$ and sevoflurane $(1-3 \%)$ were used to maintain anesthesia during surgery. After prosthesis insertion, propofol $(4 \mathrm{mg}$ per $\mathrm{kg}$ per h) and remifentanil $(0.1 \mu \mathrm{g}$ per $\mathrm{kg}$ per min) were used to maintain anesthesia. Anesthetic drugs were discontinued before wound closure. At the end of surgery, $8 \mathrm{mg}$ ondansetron was administered intravenously to all patients.

After prosthesis insertion, a periarticular infiltration of $200 \mathrm{mg}$ ropivacaine $(100 \mathrm{mg}$ per $10 \mathrm{ml}$ ) in $60 \mathrm{ml}$ of normal saline was injected all around the capsule before closure. A dose of $40 \mathrm{mg}$ of parecoxib was injected intravenously to manage pain. Postoperative pain control consisted of $50 \mathrm{mg}$ of oral voltaren (Diclofenac Sodium Sustained Release Tablets) and $10 \mathrm{mg}$ of oxycodone every $12 \mathrm{~h}$. Breakthrough pain was recorded using a Visual Analgesic Scale (VAS) score that ranged from 0 (no pain) to 10 (most severe). If the VAS score was $>6,50 \mathrm{mg}$ of pethidine was given as an intramuscular injection when required, up to every $6 \mathrm{~h}$. No nerve block or intravenous patientcontrolled analgesia was utilized perioperatively.

\section{Outcome measurements}

The primary outcome variables were the incidence of PONV, severity of PONV and complete response. Secondary outcome variables included time until first defecation and ambulation, postoperative appetite score, patient satisfaction score and length of hospital stay. A blinded clinical investigator reviewed the diagnosis and medical histories of patients and prospectively collected demographic data and surgical information. The investigator also recorded all episodes of nausea and vomiting, severity of nausea, requirement for anti-emetic rescue, and complete response during four postoperative periods $(0-6,6-12,12-24$ and $24-48$ h). Nausea was defined as a subjective unpleasant sensation associated with awareness of the urge to vomit, and vomiting was defined as the forceful expulsion of gastric contents from the mouth [16]. The incidence of nausea and vomiting was determined in each of the four periods and during the entire study by calculating the proportion of patients who experienced PONV. In order to avoid double counting, the patients experienced both nausea and vomiting would be counted as episode of vomiting.
Following institutional guidelines, $10 \mathrm{mg}$ of intramuscular metoclopramide was used as a first-line anti-emetic rescue treatment when patients experienced two or more episodes of PONV within $2 \mathrm{~h}$. This was followed by $4 \mathrm{mg}$ of intravenous ondansetron when two consecutive boluses of metoclopramide alone, delivered $30 \mathrm{~min}$ apart, were ineffective.

We used a standardized scoring algorithm to classify the severity of PONV on a 4-level scale during the 48-h observation period. Complete response was defined as no additional PONV or no requirement for anti-emetic rescue. Mild PONV described the occurrence of mild nausea or one episode of vomiting caused by exogenous stimulus (drinking or movement). Moderate PONV referred to when the patient vomited up to two times or experienced nausea that required anti-emetic rescue only once. Patients were classified as having severe PONV if they suffered more than two emetic episodes or required more than one dose of rescue anti-emetic $[17,18]$.

The same blinded investigator also recorded the time until first defecation, ambulation and length of hospital stay, and evaluated appetite score on postoperative days 0-2 as follows: 1 point, lower appetite than preoperatively; 2 points, same appetite as preoperatively; and 3 points, more appetite than preoperatively. The same investigator assessed patient satisfaction before discharge using a VAS score that ranged from 0 (extremely dissatisfied) to 10 (very satisfied). During the perioperative period, all the patients would be carefully evaluated for side effects and cardiac complications such as atrioventricular block, or QT interval prolongation with the use of electrocardiogram if necessary.

\section{Statistical analysis}

We performed a priori power analysis based on our preliminary results showing that PONV incidence was $49 \%$ in patients receiving ondansetron prophylaxis alone after total joint arthroplasty [unpublished data]. We calculated that 228 patients (76 in each arm) were required to detect a 50\% reduction in PONV incidence at an alpha level of 0.05 and a power of 0.9 using a two-sided test. To allow for exclusions and dropouts, we aimed to enroll 246 patients.

Inter-group differences in categorical variables such as incidence of PONV or proportion of complete response were assessed for significance using the chi-square or Fisher's exact tests. When differences were significant, multiple comparisons between groups were performed using a Bonferroni-corrected post hoc test. Inter-group differences in continuous variables were assessed for significance using either one-way ANOVA, in the case of body mass index, length of hospital stay, time until first defecation or ambulation; or the Wilcoxon signed-rank test, in the case of appetite and patient satisfaction 
scores. When differences were significant, multiple comparisons between groups were performed using a post hoc Tukey test. Differences associated with $p<0.05$ were considered statistically significant. All statistical analyses were conducted in SPSS 21.0 (IBM, Chicago, IL, USA).

\section{Results}

A total of 82 patients were initially allocated to each of the three groups. We excluded two patients from the control group and four from the Mosa+Dexa group because of incomplete data and spinal anesthesia. In the end, 240 patients (80 in the control group, 82 in the Dexa group and 78 in the Mosa+Dexa group) were included in the final analysis (Fig. 1). These groups showed no significant differences in clinical or demographic characteristics (Table 1).

Prophylactic use of concurrent dexamethasone and oral mosapride reduced the overall incidence and severity of PONV, and improved the overall complete response during the entire 48-h evaluation period. Across the entire evaluation period, incidence of postoperative nausea was lowest in the Mosa+Dexa group (6.4\%), followed by the Dexa group (19.5\%) and the control group (43.8\%) $(p<0.01$ for all, Table 2$)$. Similarly, incidence of postoperative vomiting was lowest in the Mosa+Dexa group (3.9\%), followed by the Dexa group (6.1\%) and the control group (11.2\%), although these differences were not significant $(p=0.176)$. The rate of complete response was significantly higher in the Mosa+ Dexa group (89.7\%) than in the Dexa group $(74.4 \%, p=$
$0.012)$ or control group $(45 \%, p<0.001)$. The rate of severe PONV was significantly lower in the Mosa+Dexa group $(1.3 \%)$ than in the Dexa group $(7.3 \%, p=0.062)$ and control group $(18.8 \%, \mathrm{p}<0.001)$.

Simultaneous application of mosapride and dexamethasone reduced the incidence of nausea mainly during the first $12 \mathrm{~h}$ (Tables 3 and 4): the incidence during 6-12 h was significantly lower in the Mosa+Dexa group $(3.8 \%)$ than in the Dexa group $(15.9 \%, p<0.016)$ and control group $(32.5 \%, \mathrm{p}<0.016)$. Moreover, all vomiting episodes occurred during the first $12 \mathrm{~h}$ in the Mosa+ Dexa patients, while some vomiting incidents in other groups occurred later (Table 4). Nevertheless, the vomiting incidence during the first $12 \mathrm{~h}$ did not differ significantly among the three groups. Less patients in Mosa+ Dexa group (2.6\%) required rescue treatment for PONV when compared with Dexa group $(9.8 \%, p=0.06)$ and Control group (21.3\%, $p<0.001$, Table 5 ), as well as total dose of metoclopramide. No significances were detected among the three groups regarding the postoperative pain score and rescue requirement.

The preemptive use of mosapride also reduced the time until first defecation, which was significantly shorter in the Mosa+Dexa group $(36.4 \pm 18.3 \mathrm{~h})$ than in the Dexa group $(54.7 \pm 15.8 \mathrm{~h}, p<0.001)$ and control group $(60.7 \pm 24.6 \mathrm{~h}, \mathrm{p}<0.001$; Table 6$)$. Appetite score was significantly higher in the Mosa+Dexa group than in the control group on postoperative days $0(p=0.019), 1$ $(p<0.001)$ and $2(p=0.022)$; and higher than in the Dexa group on postoperative day $1(p=0.001$; Table 6$)$.

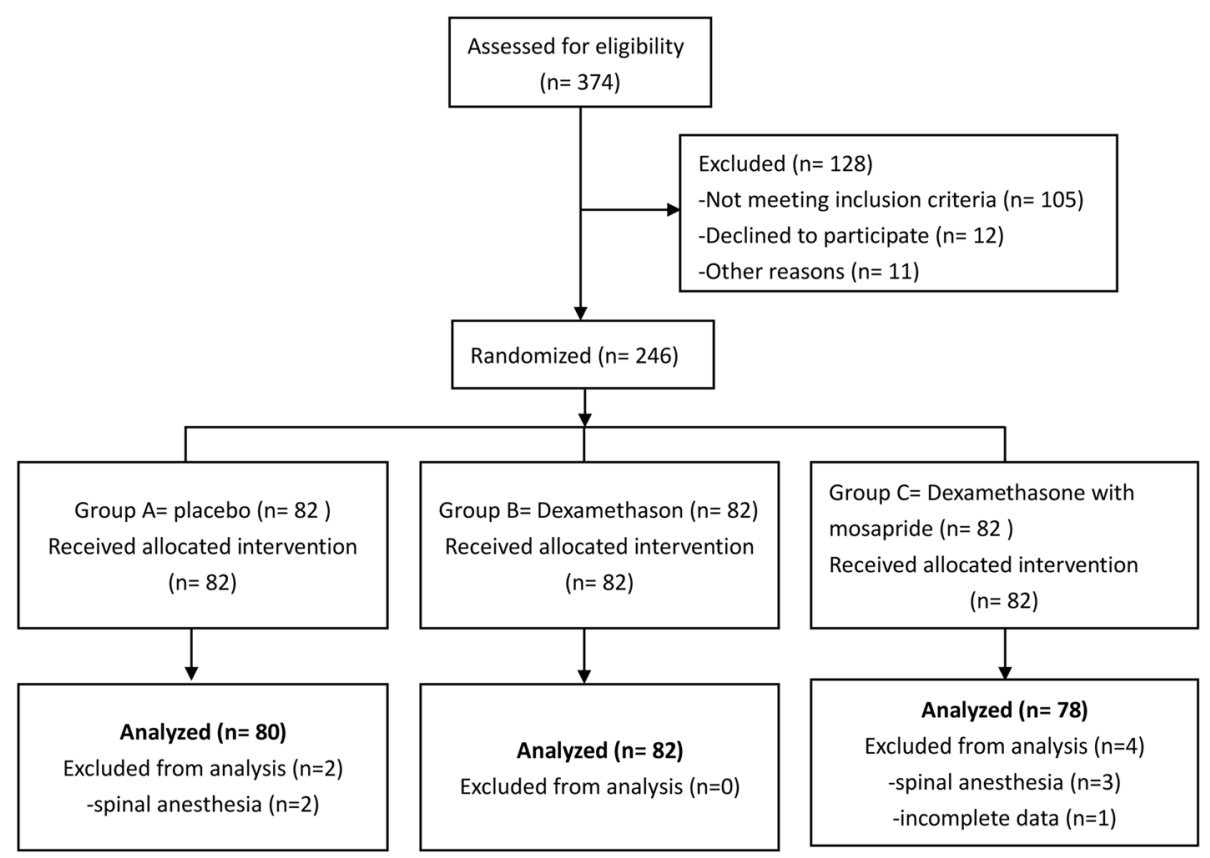

Fig. 1 A flow diagram shows the patients recruitment 
Table 1 Baseline characteristics of all patients

\begin{tabular}{|c|c|c|c|c|}
\hline & $\begin{array}{l}\text { Control } \\
(n=80)\end{array}$ & $\begin{array}{l}\text { Dexa } \\
(n=82)\end{array}$ & $\begin{array}{l}\text { Mosa+Dexa } \\
(n=78)\end{array}$ & $p$ \\
\hline Age (years) & $61.2(8.9)$ & $62.7(11.8)$ & $62.2(12.5)$ & 0.376 \\
\hline Female / Male & $47 / 33$ & $61 / 21$ & $53 / 25$ & 0.104 \\
\hline Height (m) & $1.61(0.07)$ & $1.58(0.07)$ & $1.59(0.06)$ & 0.055 \\
\hline Weight (kg) & $63.4(13.5)$ & $62.2(9.0)$ & $60.1(8.7)$ & 0.143 \\
\hline $\mathrm{BMI}\left(\mathrm{kg} / \mathrm{m}^{2}\right)$ & $24.4(4.6)$ & $24.9(3.4)$ & $23.5(3.0)$ & 0.057 \\
\hline Smoking & & & & 0.266 \\
\hline Yes & $33(41.2 \%)$ & $24(29.3 \%)$ & $26(33.3 \%)$ & \\
\hline No & $47(58.8 \%)$ & $58(70.7 \%)$ & $52(66.7 \%)$ & \\
\hline History of PONV & & & & 0.856 \\
\hline Yes & $10(12.5 \%)$ & $8(9.8 \%)$ & $10(12.8 \%)$ & \\
\hline No & $70(87.5 \%)$ & $74(91.2 \%)$ & $68(87.2 \%)$ & \\
\hline History of motion sickness & & & & 0.994 \\
\hline Yes & 27 (33.8\%) & $28(34.1 \%)$ & $33(42.3 \%)$ & \\
\hline No & $53(66.2 \%)$ & $54(65.9 \%)$ & $45(57.7 \%)$ & \\
\hline ASA Score & & & & 0.806 \\
\hline 2 & $56(70 \%)$ & $55(67.1 \%)$ & $56(71.8 \%)$ & \\
\hline 3 & $24(30 \%)$ & $27(32.9 \%)$ & $22(28.2 \%)$ & \\
\hline Surgery & & & & 0.439 \\
\hline THA & $36(45 \%)$ & $31(37.8 \%)$ & $37(47.4 \%)$ & \\
\hline TKA & $44(55 \%)$ & $51(62.2 \%)$ & $41(52.6 \%)$ & \\
\hline Number of comorbidities & & & & 0.978 \\
\hline 1 & $52(65 \%)$ & $52(63.4 \%)$ & $50(64.1 \%)$ & \\
\hline$\geq 2$ & $28(35 \%)$ & $30(36.6 \%)$ & $28(35.9 \%)$ & \\
\hline Operation time (min) & $76.3(21.6)$ & $77.6(20.1)$ & $76.2(27.8)$ & 0.920 \\
\hline Anesthesia time (min) & $125.5(26.0)$ & $127.1(26.5)$ & $120.1(33.6)$ & 0.280 \\
\hline PACU time (min) & $70.3(48.5)$ & $80.9(44.7)$ & $76.1(35.5)$ & 0.300 \\
\hline Sufentanil $(\mu \mathrm{g})$ & $24.24(2.92)$ & $24.18(2.59)$ & $24.89(3.17)$ & 0.195 \\
\hline Remifentanil (mg) & $0.58(0.15)$ & $0.62(0.10)$ & $0.62(0.30)$ & 0.329 \\
\hline Propofol (mg) & $219.45(109.40)$ & $196.93(79.12)$ & 220.54 (178.85) & 0.420 \\
\hline Midazolam (mg) & $2.09(0.51)$ & $2.12(0.41)$ & $2.11(0.48)$ & 0.946 \\
\hline Atracurium (mg) & $13.19(1.91)$ & $13.37(2.60)$ & $13.65(2.18)$ & 0.436 \\
\hline Sevoflurane (ml) & $29.97(6.71)$ & $30.23(5.47)$ & $30.53(11.11)$ & 0.913 \\
\hline VAS pain score- rest & $3.81(1.98)$ & $3.58(1.55)$ & $3.42(1.26)$ & 0.374 \\
\hline
\end{tabular}

Data presented as mean (stand deviation) or number (percentage)

ASA American Society of Anesthesiologists; BMI body mass index; Dexa dexamethasone; Mosa mosapride; THA total hip arthroplasty; TKA total knee arthroplasty; $P A C U$, post-anesthesia care unit

Patients in the Mosa+Dexa group began to ambulate $20.6 \pm 5.9 \mathrm{~h}$ after surgery, significantly sooner than patients in the Dexa group $(23.4 \pm 5.8 \mathrm{~h}, p=0.005)$ or control group (23.3 $\pm 4.6 \mathrm{~h}, p=0.008)$. Patients in the Mosa+ Dexa group were more satisfied with their hospital experience than patients in the control group $(\mathrm{p}<0.001)$ and Dexa group $(\mathrm{p}=0.008)$. Length of hospitalization was shorter in the Mosa+Dexa group than in the contrl group ( $4.9 \pm 1.4$ vs $5.6 \pm 1.5 \mathrm{~d}, p=0.012)$.

No adverse events associated with mosapride including prolonged QT syndrome were observed during the study or follow-up. A total of 5 patients (including 1 abdominal pain, 2 dry mouth, 2 insomnia) experienced side effects in control group, 5 patients (1 diarrhea, 1 dry 
Table 2 Incidence of PONV during the first postoperative $48 \mathrm{~h}$

\begin{tabular}{|c|c|c|c|c|c|c|c|}
\hline & $\begin{array}{l}\text { Control } \\
(n=80)\end{array}$ & $\begin{array}{l}\text { Dexa } \\
(n=82)\end{array}$ & $\begin{array}{l}\text { Mosa + Dexa } \\
(n=78)\end{array}$ & $p^{*}$ & $\mathrm{p} 1^{\dagger}$ & $\mathrm{p}^{\dagger}$ & $\mathrm{p3}^{+}$ \\
\hline Total & $44(55 \%)$ & $21(25.6 \%)$ & $8(10.3 \%)$ & $<0.001$ & $<0.001$ & $<0.001$ & 0.014 \\
\hline Nausea & $35(43.8 \%)$ & $16(19.5 \%)$ & $5(6.4 \%)$ & $<0.001$ & 0.001 & $<0.001$ & 0.014 \\
\hline Vomiting & $9(11.2 \%)$ & $5(6.1 \%)$ & $3(3.9 \%)$ & 0.176 & NA & NA & NA \\
\hline Complete response & $36(45 \%)$ & $61(74.4 \%)$ & $70(89.7 \%)$ & $<0.001$ & $<0.001$ & $<0.001$ & 0.012 \\
\hline Severe PONV & $15(18.8 \%)$ & $6(7.3 \%)$ & $1(1.3 \%)$ & 0.001 & 0.030 & $<0.001$ & 0.062 \\
\hline
\end{tabular}

Data presented as number of patients (percentage)

Dexa dexamethasone; Mosa mosapride; PONV postoperative nausea and vomiting

* Uncorrected $p$ values (for the three-way comparison)

${ }^{+}$Bonferroni-corrected $p$ values: p1, Control vs Dexa; p2, Control vs. Mosa+Dexa; p3, Dexa vs. Mosa-Dexa. The corrected significance threshold was 0.016

mouth, 3 insomnia) in Dexa group and 6 (in abdominal pain, 2 dry mouth and 3 insomnia) in Mosa + Dexa group without significance $(p=0.908$, Table 7$)$.

\section{Discussion}

PONV remains a challenge in recovery after total joint arthroplasty surgery, because it creates anxiety in patients, lowers their appetite, delays ambulation and even disturbs water and electrolyte balance. This increases risk of postoperative complications and prolongs hospitalization and consensus guidelines have been formulated for the management of PONV [7]. Fifteen years have passed since the first international recommendations for the prophylaxis and treatment of PONV [19], and the incidence of PONV has fallen from approximately $80 \%$ to $20-30 \%$ [20], which is still relatively high. Our own work suggests that at least certain patient populations may show much higher incidence: we reported, for example, $48 \%$ incidence in patients who underwent total joint arthroplasty with general anesthesia [unpublished data]. Indeed, risk of PONV appears to be 11-fold higher when surgery is performed under general anesthesia than under regional anesthesia [21]. While modification of risk factors should be taken firstly according to the recommendation of latest consensus [7], some risk factors such as gender or history of smoking and PONV were non-modifiable. Moreover, in our country, total joint arthroplasty is performed under general anesthesia routinely, because of the different medical system. On the other hand, spinal anesthesia is conductive to early ambulation and postoperative anticoagulation following enhanced total joint arthroplasty. These considerations highlight the need to improve PONV prophylaxis and treatment.

In our current study, we compared a new multimodal PONV prophylaxis protocol with a traditional antiemetic protocol involving ondansetron and/or dexamethasone. The latter two drugs are the most commonly used perioperatively to prevent PONV. Our results indicate that addition of the oral prokinetic drug mosapride can lead to lower PONV incidence and severity, especially postoperative nausea, during the first $12 \mathrm{~h}$ postoperatively than the use of ondansetron alone or in combination with dexamethasone, although the

Table 3 Timing of PONV events during the postoperative period

\begin{tabular}{|c|c|c|c|c|c|c|c|}
\hline Time & $\begin{array}{l}\text { Control } \\
(n=80)\end{array}$ & $\begin{array}{l}\text { Dexa } \\
(n=82)\end{array}$ & $\begin{array}{l}\text { Mosa+Dexa } \\
(n=78)\end{array}$ & $\mathbf{p}^{*}$ & $\mathrm{p} 1^{\dagger}$ & $\mathrm{p2}^{\dagger}$ & $p 3^{\dagger}$ \\
\hline Nausea & $35(43.8 \%)$ & 16 (19.5\%) & 5 (6.4\%) & $<0.001$ & 0.001 & $<0.001$ & 0.014 \\
\hline $0-6 h$ & 30 (37.5\%) & $14(17.1 \%)$ & 5 (6.4\%) & $<0.001$ & 0.003 & $<0.001$ & 0.037 \\
\hline $6-12 \mathrm{~h}$ & 26 (32.5\%) & 13 (15.9\%) & $3(3.8 \%)$ & $<0.001$ & 0.002 & $<0.013$ & 0.011 \\
\hline $12-24 \mathrm{~h}$ & $8(10 \%)$ & $3(3.7 \%)$ & 0 & 0.006 & 0.109 & 0.007 & 0.246 \\
\hline $24-48 \mathrm{~h}$ & $6(7.5 \%)$ & $1(1.2 \%)$ & 0 & 0.013 & 0.062 & 0.028 & 1.000 \\
\hline Vomiting & 9 (11.2\%) & 5 (6.1\%) & 3 (3.9\%) & 0.176 & & & \\
\hline $0-6 h$ & 7 (23.8\%) & 4 (12.2\%) & $3(3.8 \%)$ & 0.380 & & & \\
\hline $6-12 \mathrm{~h}$ & $3(12.5 \%)$ & 2 (6.1\%) & $1(1.3 \%)$ & 0.610 & & & \\
\hline $12-24 h$ & $1(1.3 \%)$ & $1(1.2 \%)$ & 0 & 1.000 & & & \\
\hline 24-48 h & $1(1.3 \%)$ & 0 & 0 & 0.652 & & & \\
\hline
\end{tabular}

Data presented as number of patients (percentage). Dexa, dexamethasone; Mosa, mosapride; PONV, postoperative nausea and vomiting

* Uncorrected values

+ Bonferroni-corrected p values: p1, Control vs Dexa; p2, Control vs. Mosa+Dexa; p3, Dexa vs. Mosa-Dexa. The corrected significance threshold was 0.016 
Table 4 Duration of PONV during the first postoperative $48 \mathrm{~h}$

\begin{tabular}{lllllll}
\hline Duration & $\begin{array}{l}\text { Control } \\
(\mathbf{n = 8 0})\end{array}$ & $\begin{array}{l}\text { Dexa } \\
(\mathbf{n = 8 2})\end{array}$ & $\begin{array}{l}\text { Mosa+Dexa } \\
(\mathbf{n = 7 8 )}\end{array}$ & $\mathbf{p}^{\mathbf{*}}$ & $\mathbf{p 1}^{\mathbf{+}}$ & $\mathbf{p 2}^{\dagger}$ \\
\hline$<6 \mathrm{~h}$ & $18(22.5 \%)$ & $12(14.6 \%)$ & $7(9.0 \%)$ & 0.061 & & \\
$6-12 \mathrm{~h}$ & $8(10.0 \%)$ & $6(7.3 \%)$ & $1(1.3 \%)$ & 0.068 & & \\
$12-24 \mathrm{~h}$ & $8(10.0 \%)$ & $2(2.4 \%)$ & 0 & 0.004 & 0.046 & 0.007 \\
$>24 \mathrm{~h}$ & $10(12.5 \%)$ & $1(1.2 \%)$ & 0 & $<0.001$ & 0.004 & 0.001 \\
\hline
\end{tabular}

Data presented as number of patients (percentage)

* Uncorrected values

† Bonferroni-corrected p values: p1, Control vs Dexa; p2, Control vs. Mosa+Dexa; p3, Dexa vs. Mosa-Dexa. The corrected significance threshold was 0.016

difference of severe PONV rate between Dexa + Mosa group and Dexa Group was not statistically significant $(p=0.062)$. Moreover, preemptive application of oral mosapride can improve appetite, bowel function, time until ambulation and length of hospital stay.

$5-\mathrm{HT}_{3}$ receptor antagonists and corticosteroids are the anti-emetic drugs most commonly used perioperatively to prevent and treat PONV. These drugs act by antagonizing $5-\mathrm{HT}_{3}$ receptors both peripherally on vagal afferents and centrally in the area postrema. Dexamethasone is a synthetic glucocorticoid showing higher potency, greater bioavailability, and longer acting time than the most widely used antagonist, ondansetron [22-24]. Lowdose systemic dexamethasone can show good anti-emetic efficacy $[25,26]$, although the mechanism remains unclear. The drug may inhibit prostaglandin synthesis and endogenous opioid release, controlling pain and reducing the need for opioid drugs, which can help prevent PONV. The half-life of dexamethasone is about $36-72 \mathrm{~h}$, much longer than the $4 \mathrm{~h}$ of ondansetron $[22,23]$. Therefore, the combination of dexamethasone and ondansetron can be particularly effective at reducing PONV incidence during the first $12-48 \mathrm{~h}$ after surgery (Tables 3 and 4 ). We found that combining dexamethasone with ondansetron led to lower incidence of PONV and higher incidence of complete response than with ondansetron alone. Similarly, previous work showed that combining dexamethasone with ramosetron further reduced postoperative emesis and pain without increasing risk of wound complications [27]. Studies also have suggested that dexamethasone can help reduce postoperative pain and inflammatory responses [11, 12, 24, 27, 28], which we did not examine here. Future work should explore the full range of benefits offered by dexamethasone.

Here we investigated additional clinical benefits of the anti-emetic mosapride, a selective $5-\mathrm{HT}_{4}$ receptor agonist. Mosapride can promote the release of acetylcholine and stimulate the gastrointestinal tract to promote motility, thereby improving the gastrointestinal symptoms of patients with functional dyspepsia. Mosapride can inhibit emesis induced by selective serotonin reuptake inhibitors (SSRIs) in laboratory animals [14], probably by reversing the SSRI-induced delay in gastric emptying. We found in the present study that the preemptive use of oral mosapride can provide additional anti-emetic effects beyond dexamethasone and ondansetron in total joint arthroplasty patients. In fact, mosapride may antagonize the ability of $5-\mathrm{HT}_{3}$ receptor antagonists to reduce gastrointestinal motility, which may help reduce the risk of constipation that affects many total hip and knee arthroplasty patients [29]. Indeed, this motilityinducing effect may help explain why the patients in our Mosa+Dexa group showed better postoperative appetite and shorter times to first defecation and ambulation

Table $\mathbf{5}$ The requirement of rescue treatment and postoperative VAS pain score

\begin{tabular}{|c|c|c|c|c|c|c|c|}
\hline & $\begin{array}{l}\text { Control } \\
(n=80)\end{array}$ & $\begin{array}{l}\text { Dexa } \\
(n=82)\end{array}$ & $\begin{array}{l}\text { Mosa+Dexa } \\
(n=78)\end{array}$ & $\mathrm{p}^{*}$ & $\mathrm{p} 1^{+}$ & $\mathrm{p} 2^{\dagger}$ & $\mathrm{p3}^{+}$ \\
\hline \multicolumn{8}{|l|}{ Metoclopramide } \\
\hline Number & $17(21.3 \%)$ & $8(9.8 \%)$ & $2(2.6 \%)$ & 0.001 & 0.043 & $<0.001$ & 0.060 \\
\hline Mean dose (mg) & $2.88(40)$ & $1.10(20)$ & $0.26(10)$ & 0.002 & 0.044 & 0.002 & 0.496 \\
\hline VAS-rest $24 \mathrm{~h}$ & $2.66 \pm 0.72$ & $2.45 \pm 0.91$ & $2.59 \pm 0.82$ & 0.333 & & & \\
\hline VAS-rest $48 \mathrm{~h}$ & $2.16 \pm 0.99$ & $2.03 \pm 0.73$ & $2.15 \pm 0.71$ & 0.551 & & & \\
\hline \multicolumn{8}{|l|}{ Pethidine } \\
\hline Number & 30 (37.5\%) & $19(23.2 \%)$ & $21(26.9 \%)$ & 0.116 & & & \\
\hline Mean dose (mg) & $20(100)$ & $17.38(50)$ & $16.99(100)$ & 0.486 & & & \\
\hline
\end{tabular}

Data presented as number of patients (percentage), mean (range) or mean \pm standard deviation. Dexa dexamethasone; Mosa mosapride

* Uncorrected $p$ values (for the three-way comparison)

+ Bonferroni-corrected $p$ values: p1, Control vs Dexa; p2, Control vs. Mosa+Dexa; p3, Dexa vs. Mosa-Dexa. The corrected significance threshold was 0.016 
Table 6 Other clinical outcomes

\begin{tabular}{|c|c|c|c|c|c|c|c|}
\hline & $\begin{array}{l}\text { Control } \\
(n=80)\end{array}$ & $\begin{array}{l}\text { Dexa } \\
(n=82)\end{array}$ & $\begin{array}{l}\text { Mosa+Dexa } \\
(n=78)\end{array}$ & $\mathrm{p}^{*}$ & $\mathrm{p} 1^{\dagger}$ & $\mathrm{p} 2^{+}$ & $p 3^{+}$ \\
\hline Time to first defecation (h) & $60.7 \pm 24.6$ & $54.7 \pm 15.8$ & $36.4 \pm 18.3$ & $<0.001$ & 0.136 & $<0.001$ & $<0.001$ \\
\hline Appetite on POD 0 & $2.26 \pm 0.67$ & $2.34 \pm 0.65$ & $2.55 \pm 0.68$ & 0.020 & 0.731 & 0.019 & 0.117 \\
\hline Appetite on POD 1 & $2.38 \pm 0.62$ & $2.41 \pm 0.63$ & $2.76 \pm 0.51$ & $<0.001$ & 0.905 & $<0.001$ & 0.001 \\
\hline Appetite on POD 2 & $2.63 \pm 0.49$ & $2.73 \pm 0.45$ & $2.82 \pm 0.45$ & 0.030 & 0.306 & 0.022 & 0.443 \\
\hline Time to first ambulation (h) & $23.4 \pm 5.8$ & $23.3 \pm 4.6$ & $20.6 \pm 5.9$ & 0.002 & 0.976 & 0.005 & 0.008 \\
\hline Satisfaction & $7.7 \pm 1.1$ & $8.7 \pm 1.1$ & $9.2 \pm 0.9$ & $<0.001$ & $<0.001$ & $<0.001$ & 0.008 \\
\hline Length of hospitalization (d) & $5.6 \pm 1.5$ & $5.1 \pm 1.5$ & $4.9 \pm 1.4$ & 0.013 & 0.095 & 0.012 & 0.683 \\
\hline
\end{tabular}

Data presented as mean \pm standard deviation. Dexa, dexamethasone; Mosa, mosapride; POD, postoperative day p1, Control vs Dexa; p2, Control vs. Mosa+Dexa; p3, Dexa vs. Mosa-Dexa. * $p$ values with one-way ANOVA or Wilcoxon signed-rank test and ${ }^{\dagger} p$ values with Tukey post hoc test

than patients who did not receive mosapride. Although some patients in Mosa + Dexa group experienced digestive side effects such as abdominal pain or dry mouth, we could not conclude the correlation between mosapride and these side effects because of non-significant difference.

As far as we know, our study provides comprehensive evidence supporting the potential clinical benefit of prokinetic drugs following total joint arthroplasty, although the results need to be interpreted in light of the following limitations. First, patients receiving mosapride alone were not included. Therefore, we cannot make the conclusion that mosapride alone was effective at reducing PONV incidence after total joint arthroplasty. Although our results implicated no incidence of prolonged QT syndrome, more further works are needed to confirm and extend our results, especially the safety profile of mosapride, because another $5-\mathrm{HT}_{4}$ agonist that antagonizes $5-\mathrm{HT}_{3}$ activity and that can rapidly relieve nausea induced by SSRIs was withdrawn for cardiotoxicity [30]. Second, the sample number was calculated according to our primary outcome of PONV incidence. As a result, the sample may not have been adequately powered to detect inter-group differences in secondary outcomes, such as rate of severe PONV, and complication rates. Nevertheless, previous work from our group and others suggests that perioperative dexamethasone does not

Table 7 Adverse events and side effects

\begin{tabular}{lllll}
\hline & $\begin{array}{l}\text { Control } \\
(\mathbf{n = 8 0})\end{array}$ & $\begin{array}{l}\text { Dexa } \\
(\mathbf{n = 8 2})\end{array}$ & $\begin{array}{l}\text { Mosa + Dexa } \\
(\mathbf{n = 7 8 )}\end{array}$ & $\mathbf{p}^{*}$ \\
\hline Long QT syndrome & 0 & 0 & 0 & $\mathrm{NA}$ \\
Diarrhea & 0 & $1(1.22 \%)$ & 0 & 1.000 \\
Abdominal pain & $1(1.25 \%)$ & 0 & $1(1.28 \%)$ & 0.556 \\
Dry mouth & $2(2.5 \%)$ & $1(1.22 \%)$ & $2(2.56 \%)$ & 0.752 \\
Insomnia & $2(2.5 \%)$ & $3(3.66 \%)$ & $3(3.85 \%)$ & 0.908 \\
Total & $5(6.25 \%)$ & $5(6.1 \%)$ & $6(7.69 \%)$ & 0.906 \\
\hline
\end{tabular}

Data presented as mean \pm standard deviation. Dexa dexamethasone; Mosa mosapride

*p values were analyzed using Fisher's exact test increase the incidence of postoperative infection in total hip and knee arthroplasty [11, 12, 31]. Third, all participants in our study were Chinese and most (67\%) were women. Thus, our findings may not be widely generalizable, because female gender is a wellestablished risk factor for PONV [32]. Fourth, our postoperative analgesic regimen included extensive multimodal pain control drugs and modalities such as preemptive analgesic medication and periarticular injection, which may have introduced heterogeneity into our sample. However, the rest VAS pain score at postoperative $24 \mathrm{~h}$ and $48 \mathrm{~h}$ and requirement of rescue treatment for pain were comparable among the three groups (Table 5). Fifth, our study did not investigate whether the choice of PONV management regimen affected postoperative inflammatory marker levels and pain control. This should be explored in future work, since our previous study has shown that low-dose dexamethasone can relieve postoperative pain and postoperative nausea, as well as provide additional inflammatory control and improve clinical outcomes [28]. Lastly, our study excluded diabetic patients, so future work should examine whether our results can be generalized to this patient subpopulation.

\section{Conclusion}

Prophylactic use of concurrent dexamethasone and oral mosapride can reduce overall incidence and severity of PONV, especially postoperative nausea, as well as increase complete response rates during the first $12 \mathrm{~h}$ after total hip and knee arthroplasty when compared with other patients. While it seemed that oral mosapride would not provide additional effect on reducing the rate of severe PONV when compared with dexamethasone alone. Preemptive oral mosapride can also improve postoperative appetite and bowel function.

Abbreviations

PONV: Postoperative nausea and vomiting; THA: Total hip arthroplasty; TKA: Total knee arthroplasty; ASA: American Society of Anesthesiologists; PACU: Post-anesthesia care unit; BMI: Body mass index 


\section{Acknowledgments}

We thank Xiaowei Feng, M. D (Chengdu First People's Hospital, Chengdu, China) and A. Chapin Rodriguez, PhD for helpful suggestions on the manuscript. We also thank all the patients and staff who participated in this study.

\section{Authors' contributions}

Conceptualization, FXP; Methodology, JWX and YCC; Formal analysis, JM and QH; Investigation, YCC and JWX; Resources FXP; Data curation and Writing, YCC and JWX; Project administration and Funding Acquisition, FXP and JWX. All authors have read and approved the manuscript.

\section{Funding}

The research was supported by the Post-Doctor Research Project, West China Hospital, Sichuan University (2018HXBH073); the National Clinical Research Center for Geriatrics, West China Hospital, Sichuan University (Z2018B11); and the National Health and Family Planning Commission of the People's Republic of China program (201302007).

\section{Availability of data and materials}

The datasets used and analysed during the current study are available from the corresponding author on reasonable request.

\section{Ethics approval and consent to participate}

The study protocol was approved by the Institutional Review Board of West China Hospital, Sichuan University (2012-268), and all procedures were performed according to the Declaration of Helsinki. Written informed consent was obtained prospectively from all patients prior to surgery.

\section{Consent for publication}

Not applicable.

\section{Competing interests}

The authors declare that they have no competing interests.

\section{Author details}

'Department of Orthopaedic Surgery, National Clinical Research Center for Geriatrics, West China Hospital, Sichuan University, No. 37 Guoxue Road, Chengdu, Sichuan Province 610041, People's Republic of China. ${ }^{2}$ Department of Orthopaedic Surgery, The First Affiliated Hospital of Zhengzhou University, No. 1 East Jianshe Road, Zhengzhou 450052, People's Republic of China.

\section{Received: 24 August 2020 Accepted: 29 November 2020}

\section{Published online: 03 December 2020}

\section{References}

1. Kurtz S, Ong K, Lau E, Mowat F, Halpern M. Projections of primary and revision hip and knee arthroplasty in the United States from 2005 to 2030. $J$ Bone Joint Surg Am. 2007:89(4):780-5. https://doi.org/10.2106/JBJS.F.00222

2. Patel A, Pavlou G, Mujica-Mota RE, Toms AD. The epidemiology of revision total knee and hip arthroplasty in England and Wales: a comparative analysis with projections for the United States. A study using the National Joint Registry dataset. Bone Joint J. 2015;97-B(8):1076-81. https://doi.org/10. 1302/0301-620X.97B8.35170

3. Lin CJ, Williams BA. Postoperative nausea and vomiting in ambulatory regional anesthesia. Int Anesthesiol Clin. 2011;49(4):134-43. https://doi.org/ 10.1097/AlA.0b013e318216bf9c

4. Sansonnens J, Taffe P, Burnand B, group ADSs. Higher occurrence of nausea and vomiting after total hip arthroplasty using general versus spinal anesthesia: an observational study. BMC Anesthesiol. 2016;16(1):44. https:// doi.org/10.1186/s12871-016-0207-0

5. Sculco PK, Pagnano MW. Perioperative solutions for rapid recovery joint arthroplasty: get ahead and stay ahead. J Arthroplast. 2015;30(4):518-20. https://doi.org/10.1016/j.arth.2015.01.036.

6. Kehlet H. Fast-track hip and knee arthroplasty. Lancet. 2013;381(9878):16002. https://doi.org/10.1016/S0140-6736(13)61003-X.

7. Gan TJ, Diemunsch P, Habib AS, Kovac A, Kranke P, Meyer TA, Watcha M, Chung F, Angus S, Apfel CC, Bergese SD, Candiotti KA, Chan MT, Davis PJ, Hooper VD, Lagoo-Deenadayalan S, Myles P, Nezat G, Philip BK, Tramer MR, Society for Ambulatory A. Consensus guidelines for the management of postoperative nausea and vomiting. Anesth Analg. 2014;118(1):85-113. https://doi.org/10.1213/ANE.0000000000000002.

8. Kranke P, Diemunsch P. The 2014 consensus guidelines for the management of postoperative nausea and vomiting: a leapfrog towards a postoperative nausea and vomiting-free hospital. Eur J Anaesthesiol. 2014; 31(12):651-3. https://doi.org/10.1097/EJA.0000000000000080.

9. Eberhart LH, Kranke P. Postoperative nausea and vomiting: is everything now solved or still more questions than answers? Eur J Anaesthesiol. 2016; 33(12):878-80. https://doi.org/10.1097/EJA.0000000000000527.

10. Ross-Adjie GM, Monterosso L, Bulsara M. Bowel management post major joint arthroplasty: results from a randomised controlled trial. Int J Orthop Trauma Nurs. 2015;19(2):92-101. https://doi.org/10.1016/j.jotn.2014.04.002.

11. Xu B, Ma J, Huang Q, Huang ZY, Zhang SY, Pei FX. Two doses of low-dose perioperative dexamethasone improve the clinical outcome after total knee arthroplasty: a randomized controlled study. Knee Surg Sports Traumatol Arthrosc. 2018;26(5):1549-56. https://doi.org/10.1007/s00167-017-4506-X.

12. Lei YT, Xu B, Xie XW, Xie JW, Huang Q, Pei FX. The efficacy and safety of two low-dose peri-operative dexamethasone on pain and recovery following total hip arthroplasty: a randomized controlled trial. Int Orthop. 2018;42(3):499-505. https://doi.org/10.1007/s00264-017-3537-8.

13. Dorn S, Lembo A, Cremonini F. Opioid-induced bowel dysfunction: epidemiology, pathophysiology, diagnosis, and initial therapeutic approach. Am J Gastroenterol Suppl. 2014;2(1):31-7. https://doi.org/10.1038/ajgsup.2014.7.

14. Mine Y, Oku S, Yoshida N. Anti-emetic effect of mosapride citrate hydrate, a 5-HT4 receptor agonist, on selective serotonin reuptake inhibitors (SSRIs)induced emesis in experimental animals. J Pharmacol Sci. 2013;121(1):58-66. https://doi.org/10.1254/jphs.12175fp.

15. Ganesan P, Sharma A, Mohanti BK, Gogia A. Protracted cisplatin-induced vomiting responding to mosapride. Indian J Cancer. 2010;47(1):73-4. https:// doi.org/10.4103/0019-509X.58866.

16. Watcha MF, White PF. Postoperative nausea and vomiting. Its etiology, treatment, and prevention. Anesthesiology. 1992;77(1):162-84. https://doi. org/10.1097/00000542-199207000-00023.

17. Xiang $Y$, Ye W, Sun N, Jin X. Analgesic and sedative effects of Dezocine and midazolam during Vitrectomy. Curr Eye Res. 2016;41(11):1460-4. https://doi. org/10.3109/02713683.2015.1128551.

18. Reibaldi M, Fallico M, Longo A, Avitabile T, Astuto M, Murabito P, Minardi C, Bonfiglio V, Boscia F, Furino C, Rejdak R, Nowomiejska K, Toro M, Cennamo G, Cillino S, Rinaldi M, Fiore T, Cagini C, Russo A. Efficacy of three different prophylactic treatments for postoperative nausea and vomiting after Vitrectomy: a randomized clinical trial. J Clin Med. 2019;8(3). https://doi.org/10.3390/jcm8030391.

19. Gan TJ, Meyer T, Apfel CC, Chung F, Davis PJ, Eubanks S, Kovac A, Philip BK, Sessler DI, Temo J, Tramer MR, Watcha M, Department of Anesthesiology DUMC. Consensus guidelines for managing postoperative nausea and vomiting. Anesth Analg. 2003;97(1):62-71, table of contents. https://doi.org/ 10.1213/01.ane.0000068580.00245.95.

20. Habib AS, Gan TJ. Postoperative nausea and vomiting: then \& now. Anesth Analg. 2012;115(3):493-5. https://doi.org/10.1213/ANE.0b013e318254285e.

21. Sinclair DR, Chung F, Mezei G. Can postoperative nausea and vomiting be predicted? Anesthesiology. 1999;91(1):109-18. https://doi.org/10.1097/ 00000542-199907000-00018

22. Spies CM, Strehl C, van der Goes MC, Bijlsma JW, Buttgereit F. Glucocorticoids. Best Pract Res Clin Rheumatol. 2011;25(6):891-900. https:// doi.org/10.1016/j.berh.2011.11.002.

23. Coutinho AE, Chapman KE. The anti-inflammatory and immunosuppressive effects of glucocorticoids, recent developments and mechanistic insights. Mol Cell Endocrinol. 2011;335(1):2-13. https://doi.org/10.1016/.j.mce.2010.04.005.

24. D'Souza N, Swami M, Bhagwat S. Comparative study of dexamethasone and ondansetron for prophylaxis of postoperative nausea and vomiting in laparoscopic gynecologic surgery. Int J Gynaecol Obstet. 2011;113(2):124-7. https://doi.org/10.1016/j.jgo.2010.11.022.

25. Lunn TH, Kehlet H. Perioperative glucocorticoids in hip and knee surgery benefit vs. harm? A review of randomized clinical trials. Acta Anaesthesiol Scand. 2013;57(7):823-34. https://doi.org/10.1111/aas.12115.

26. Kardash KJ, Sarrazin F, Tessler MJ, Velly AM. Single-dose dexamethasone reduces dynamic pain after total hip arthroplasty. Anesth Analg. 2008;106(4): 1253-7, table of contents. https://doi.org/10.1213/ANE.0b013e318164f319.

27. Koh IJ, Chang CB, Lee JH, Jeon YT, Kim TK. Preemptive low-dose dexamethasone reduces postoperative emesis and pain after TKA: a randomized controlled study. Clin Orthop Relat Res. 2013;471(9):3010-20. https://doi.org/10.1007/s11999-013-3032-5. 
28. Lei Y, Huang Q, Xu B, Zhang S, Cao G, Pei F. Multiple low-dose dexamethasone further improves clinical outcomes following Total hip Arthroplasty. J Arthroplast. 2018;33(5):1426-31. https://doi.org/10.1016/j.arth. 2017.11.057.

29. Ho J, Kuhn RJ, Smith KM. Update on treatment options for constipation. Orthopedics. 2008;31(6):570-4. https://doi.org/10.3928/01477447-20080601-12.

30. Bergeron R, Blier P. Cisapride for the treatment of nausea produced by selective serotonin reuptake inhibitors. Am J Psychiatry. 1994;151(7):1084-6. https://doi.org/10.1176/ajp.151.7.1084.

31. Richardson AB, Bala A, Wellman SS, Attarian DE, Bolognesi MP, Grant SA. Perioperative dexamethasone administration does not increase the incidence of postoperative infection in Total hip and knee Arthroplasty: a retrospective analysis. J Arthroplast. 2016;31(8):1784-7. https://doi.org/10. 1016/j.arth.2016.01.028.

32. Gan TJ. Risk factors for postoperative nausea and vomiting. Anesth Analg. 2006;102(6):1884-98. https://doi.org/10.1213/01.ANE.0000219597.16143.4D.

\section{Publisher's Note}

Springer Nature remains neutral with regard to jurisdictional claims in published maps and institutional affiliations.

Ready to submit your research? Choose BMC and benefit from:

- fast, convenient online submission

- thorough peer review by experienced researchers in your field

- rapid publication on acceptance

- support for research data, including large and complex data types

- gold Open Access which fosters wider collaboration and increased citations

- maximum visibility for your research: over $100 \mathrm{M}$ website views per year

At $\mathrm{BMC}$, research is always in progress.

Learn more biomedcentral.com/submissions 